\title{
Comparison of a dietary portfolio diet of cholesterol-lowering foods and a statin on LDL particle size phenotype in hypercholesterolaemic participants
}

\author{
Iris Gigleux ${ }^{1}$, David J. A. Jenkins ${ }^{2}$, Cyril W. C. Kendall ${ }^{2}$, Augustine Marchie ${ }^{2}$, Dorothea A. Faulkner ${ }^{2}$, \\ Julia M. W. Wong ${ }^{2}$, Russell de Souza ${ }^{2}$, Azadeh Emam², Tina L. Parker ${ }^{2}$, Elke A. Trautwein ${ }^{3}$, \\ Karen G. Lapsley ${ }^{4}$, Philip W. Connelly ${ }^{5}$ and Benô̂t Lamarche ${ }^{1 *}$ \\ ${ }^{1}$ Institute of Nutraceuticals and Functional Foods, Laval University, Quebec, Canada \\ ${ }^{2}$ Clinical Nutrition and Risk Factor Modification Center, St. Michael's Hospital, Toronto, Ontario, Canada \\ ${ }^{3}$ The Unilever Food and Health Research Institute, Unilever R\&D, Vlaardingen, The Netherlands \\ ${ }^{4}$ Almond Board of California, Modesto, CA, USA \\ ${ }^{5}$ Departments of Medicine and Laboratory Medicine and Pathobiology, University of Toronto; Keenan Research Center \\ in the Li Ka Shing Knowledge Institute, St. Michael's Hospital, Toronto, Ontario, Canada \\ (Received 6 November 2006 - Revised 20 April 2007 - Accepted 21 May 2007)
}

\begin{abstract}
The effect of diet $v$. statins on LDL particle size as a risk factor for CVD has not been examined. We compared, in the same subjects, the impact of a dietary portfolio of cholesterol-lowering foods and a statin on LDL size electrophoretic characteristics. Thirty-four hyperlipidaemic subjects completed three 1-month treatments as outpatients in random order: a very-low saturated fat diet (control); the same diet with $20 \mathrm{mg}$ lovastatin; a dietary portfolio high in plant sterols $(1 \mathrm{~g} / 4200 \mathrm{~kJ})$, soya proteins $(21.4 \mathrm{~g} / 4200 \mathrm{~kJ})$, soluble fibres $(9.8 \mathrm{~g} / 4200 \mathrm{~kJ})$ and almonds $(14 \mathrm{~g} / 4200 \mathrm{~kJ})$. LDL electrophoretic characteristics were measured by non-denaturing polyacrylamide gradient gel electrophoresis of fasting plasma at 0,2 and 4 weeks of each treatment. The reductions in plasma LDL-cholesterol levels with the dietary portfolio and with statins were comparable and were largely attributable to reductions in the estimated concentration of cholesterol within the smallest subclass of LDL (portfolio - 0.69 (SE 0.10) mmol/l, statin -0.99 (SE 0.10$) \mathrm{mmol} / \mathrm{l})$. These were significantly greater $(P<0.01)$ than changes observed after the control diet $(-0.17$ (SE 0.08$)$ $\mathrm{mmol} / \mathrm{l})$. Finally, baseline C-reactive protein levels were a significant predictor of the LDL size responsiveness to the dietary portfolio but not to the other treatments. The dietary portfolio, like the statin treatment, had only minor effects on several features of the LDL size phenotype, but the pronounced reduction in cholesterol levels within the small LDL fraction may provide additional cardiovascular benefit over the traditional low-fat diet of National Cholesterol Education Program Step II.
\end{abstract}

Nutrition: Drugs: Lipids: Lipoproteins

LDL particles are heterogeneous in terms of size, density and physical properties ${ }^{1}$ and it is now being increasingly recognized that small dense LDL particles are associated with an increased risk of $\mathrm{CHD}^{2}$ even in the presence of a relatively normal LDL-cholesterol concentration ${ }^{3}$.

3-Hydroxy-3-methyl-glutaryl-coA reductase inhibitors (statins) have been shown to be effective in reducing CHD risk and mortality ${ }^{4,5}$ and have been identified as the primary pharmacological tool in the treatment of elevated LDL-cholesterol concentration $^{6}$. While some studies have shown small but significant benefits of statins on LDL particle diameter ${ }^{7}$, LDL subclass distribution $^{8}$ and on the reduction of cholesterol within the smallest LDL subfractions ${ }^{9-11}$, other studies have indicated that statins had only marginal or even no effect on LDL particle size $\mathrm{e}^{12,13}$.

Although the traditional dietary approach currently recommended by the American Heart Association has been relatively efficacious in decreasing total cholesterol and LDL-cholesterol levels ${ }^{14}$, the magnitude of these benefits is generally modest. For that reason, the National Cholesterol Education Program Adult Treatment Panel III ${ }^{15}$ and the American Heart Association ${ }^{16}$ have recently recommended an increased use of functional foods with more potent effects on reducing cholesterol levels for optimal CHD risk reduction. There is now evidence that a combination of four dietary components, with relatively limited hypercholesterolaemic effects when taken individually, may be as effective as first-generation statins in lowering LDL-cholesterol ${ }^{17}$. However, few studies have examined the impact of these dietary components taken individually on the LDL particle size phenotype $\mathrm{e}^{18-27}$ and only one study has documented the combined effect of this portfolio of cholesterol-lowering foods on the LDL size phenotype $^{28}$. The purpose of the present study was to directly compare the effect of a statin treatment with that of a combination of cholesterol-lowering food from vegetable sources (dietary portfolio) on LDL size electrophoretic characteristics. Previous studies have shown that the inflammatory state may

Abbreviations: CRP, C-reactive protein; PPD, peak particle diameter

* Corresponding author: Dr Benoît Lamarche, fax (418) 656 5877, email Benoit.Lamarche@inaf.ulaval.ca 
influence the responsiveness to dietary changes ${ }^{29-31}$. As part of the present study, we have also investigated the extent to which the inflammatory status modulated the LDL size responsiveness to the treatments.

\section{Subjects and methods}

\section{Subjects}

In the present analysis, LDL size phenotype was measured in thirty-four hyperlipidaemic participants (twenty men and fourteen postmenopausal women) who completed all three phases of a previous study devised to directly compare the effect of statin therapy and the combination of cholesterol-lowering foods on plasma LDL-cholesterol levels and other cardiovascular risk factors ${ }^{17,32}$. The mean age of the subjects was 58 (SD 8.6) years and BMI was 27.3 (SD 3.3$) \mathrm{kg} / \mathrm{m}^{2}$. The participants' characteristics at baseline are shown in Table 1 . These characteristics were similar between men and women except for age and body weight. Men were significantly younger and heavier than women $(P=0 \cdot 013$ and $P=0.001$ respectively). Most participants (twenty-nine out of thirty-four) were of European descent. Other participants were Chinese ( $n 1)$, Indian $(n 2)$, black $(n 1)$ and Hispanic $(n 1)^{17}$. Briefly, participants were recruited from patients attending the Risk Factor Modification Center, St Michael's Hospital, Toronto and from newspaper advertisements as previously described ${ }^{17}$. All participants had previously elevated LDL-cholesterol concentrations $(>4.1 \mathrm{mmol} / \mathrm{l})$. None of the participants had a history of CVD, untreated hypertension (blood pressure $>140 / 90 \mathrm{~mm} \mathrm{Hg}$ ), diabetes, renal or liver disease and none was taking medication known to influence serum lipid concentrations, apart from three women who were taking stable doses of thyroxine. One of these three women was also receiving oestrogen replacement therapy. The present study was approved by the Ethics Committees of the University of Toronto and St Michael's Hospital and written informed consent was obtained from all participants.

\section{Study protocol}

The present study was performed as a randomized crossover design and participants completed all 1-month treatments. Subjects were randomly assigned to start with either a verylow-saturated fat dairy and wholewheat cereal diet (control),

Table 1. Characteristics of study participants at baseline* $\ddagger$ (Mean values and standard deviations for thirty-four subjects)

\begin{tabular}{lcc}
\hline Characteristics & Mean & SD \\
\hline Age (years) & 58 & 9 \\
Body weight $(\mathrm{kg})$ & 76.4 & 12.8 \\
BMI $\left(\mathrm{kg} / \mathrm{m}^{2}\right)$ & 27.3 & 3.4 \\
Blood pressure $(\mathrm{mm} \mathrm{Hg})$ & & \\
$\quad$ Systolic & 121 & 12 \\
$\quad$ Diastolic & 77 & 7 \\
Plasma cholesterol† (mmol/l) & & \\
Total & 6.65 & 0.93 \\
LDL & 4.42 & 0.79 \\
$\quad$ HDL & 1.20 & 0.29 \\
Plasma TAG† (mmol/l) & 2.26 & 1.04 \\
\hline
\end{tabular}

*Adapted from Jenkins et al. ${ }^{17}$.

† To convert cholesterol and TAG to $\mathrm{mg} / \mathrm{dl}$, multiply by 38.67 and 88.57 respectively. $\ddagger$ For details of subjects and procedures, see Subjects and methods. this same diet with a statin (statin diet) or a very-low-saturated fat diet containing viscous fibres, plant sterols, soya foods and almonds (dietary portfolio). All foods were provided except for fresh fruit and vegetables. Blood samples were obtained after 12-h overnight fasts at 2-week intervals and fasting body weights were measured weekly. Weighed diet histories ( $7 \mathrm{~d})$ were obtained for the week before the 1-month treatment period.

\section{Diets}

The diets eaten by participants 4 weeks prior to beginning the study and during the 2-6 week washout periods between treatments were their routine therapeutic low-fat diets, which followed the National Cholesterol Education Program Step 2 guidelines $(\leq 7 \%$ energy from saturated fat and $<200 \mathrm{mg}$ dietary cholesterol $)^{15}$. The subjects were asked to weigh all food items consumed during the study period and during the week before treatments as previously described ${ }^{17}$.

The dietary portfolio has already been described ${ }^{17}$. Plant sterol esters incorporated in margarine provided $1.0 \mathrm{~g}$ plant sterols/4200 kJ. Soluble fibres (approximately $10 \mathrm{~g} / 4200 \mathrm{~kJ}$ diet) came from oats $(4.24 \mathrm{~g})$, barley $(1.36 \mathrm{~g})$ and psyllium $(4 \cdot 15 \mathrm{~g})$. Vegetable sources of soluble fibres were also included with emphasis on okra $(0.39 \mathrm{~g})$ and aubergine $(0 \cdot 24 \mathrm{~g})$. Soya proteins were provided $(21.4 \mathrm{~g} / 4200 \mathrm{~kJ})$ with soya milk, tofu and soya meat substitute together with $14 \mathrm{~g}$ whole almonds $/ 4200 \mathrm{~kJ}$.

The control diet contained skimmed milk, fat-free cheese and yoghurt, egg substitute and liquid egg white to achieve low intakes of saturated fat. This diet provided high intakes of fibre from wholewheat breakfast cereals $(2 \cdot 0 \mathrm{~g}$ total dietary fibre $/ 4200 \mathrm{~kJ})$, bread $(2.5 \mathrm{~g}$ total dietary fibre $/ 4200 \mathrm{~kJ})$ and wheat bran added to muffins containing a high amount of dairy protein $(7 \cdot 25 \mathrm{~g}$ total dietary fibre $/ 4200 \mathrm{~kJ}$ diet $)$. To balance the fatty acid profile of the dietary portfolio, MUFA were also incorporated into the control diet (e.g. muffins) with sunflower oil $(9 \mathrm{~g} / 4200 \mathrm{~kJ})$ and safflower oil $(5 \mathrm{~g} /$ $4200 \mathrm{~kJ})$. Table 2 shows the macronutrient profiles of the weight-maintaining diets as documented at week 4 of each treatment. Diets were analysed using a program based on US Department of Agriculture data ${ }^{33}$.

Lovastatin $(20 \mathrm{mg})$ and placebo capsules containing lactose, with one capsule to be taken in the evening for $28 \mathrm{~d}$, were dispensed by the hospital pharmacy in identical containers according to the randomization determined by the statistician.

\section{Analyses}

Data on plasma lipids and C-reactive protein (CRP) levels in the present study have already been reported ${ }^{17,32}$. LDL electrophoretic characteristics were obtained by non-denaturing polyacrylamide gradient (2-16\%) gel electrophoresis from serum stored at $-70^{\circ} \mathrm{C}$ as described previously ${ }^{3}$. The estimated diameter for the major peak in each scan was identified as the LDL- peak particle diameter (PPD). An integrated (or mean) LDL diameter was also computed ${ }^{3}$. Analysis of pooled plasma standards revealed that measurements of LDL-PPD and LDL integrated particle size were highly reproducible, with inter-assay $\mathrm{CV}$ $<1 \%$. The relative proportion of LDL having a diameter

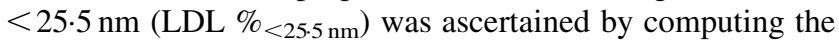


Table 2. Nutritional profile of the control, statin and portfolio diets provided to the hyperlipidaemic subjects and recorded as eaten at week 4 of each intervention ${ }^{\star} \dagger$

(Mean values and standard deviations for thirty-four subjects for each diet group)

\begin{tabular}{|c|c|c|c|c|c|c|}
\hline & \multicolumn{2}{|c|}{ Control diet } & \multicolumn{2}{|c|}{ Statin diet } & \multicolumn{2}{|c|}{ Dietary portfolio } \\
\hline & Mean & SD & Mean & SD & Mean & SD \\
\hline Energy $(\mathrm{kJ} / \mathrm{d})$ & 9811 & 2120 & 9761 & 2240 & 9899 & 2320 \\
\hline Total protein (\% energy) & $22 \cdot 1$ & 1.2 & $22 \cdot 3$ & 1.2 & 21.9 & $1 \cdot 7$ \\
\hline Vegetable protein (\% energy) & $4 \cdot 3^{a}$ & 0.6 & $4 \cdot 5^{\mathrm{a}}$ & 1.2 & $21 \cdot 6^{b}$ & $1 \cdot 7$ \\
\hline Available carbohydrate (\% energy) & $52 \cdot 6^{\mathrm{a}}$ & $2 \cdot 3$ & $52 \cdot 1^{\mathrm{a}}$ & 2.9 & $48 \cdot 7^{b}$ & $3 \cdot 5$ \\
\hline Total dietary fibre $(\mathrm{g} / 4.2 \mathrm{MJ})$ & $23 \cdot 1^{a}$ & $2 \cdot 3$ & $23 \cdot 2^{a}$ & 2.9 & $32 \cdot 8^{\mathrm{b}}$ & $2 \cdot 9$ \\
\hline Total fat (\% energy) & $24 \cdot 9^{\mathrm{a}}$ & 1.7 & $25 \cdot 1^{a}$ & $1 \cdot 7$ & $29 \cdot 2^{b}$ & $2 \cdot 9$ \\
\hline SFA (\% energy) & $4 \cdot 6^{\mathrm{a}}$ & 0.6 & $4 \cdot 7^{\mathrm{a}}$ & 0.6 & $6 \cdot 3^{b}$ & 0.6 \\
\hline MUFA (\% energy) & $10 \cdot 3^{a}$ & $1 \cdot 2$ & $10 \cdot 2^{a}$ & $1 \cdot 2$ & $12 \cdot 1^{b}$ & $2 \cdot 3$ \\
\hline PUFA (\% energy) & $8 \cdot 8^{\mathrm{a}}$ & $1 \cdot 2$ & $9 \cdot 1^{a}$ & 0.6 & $10 \cdot 0^{b}$ & $1 \cdot 2$ \\
\hline Dietary cholesterol (mg/4.2 MJ) & $12 \cdot 2^{\mathrm{a}}$ & 2.9 & $14 \cdot 4^{\mathrm{a}}$ & $7 \cdot 0$ & $24 \cdot 0^{b}$ & $6 \cdot 4$ \\
\hline Alcohol (\% energy) & 0.1 & 0.6 & 0.3 & 0.6 & 0.1 & 0.6 \\
\hline
\end{tabular}

*Adapted from Jenkins et al. ${ }^{17}$

$\dagger$ For details of subjects and procedures, see Subjects and methods.

a,b Mean values within the same row with different superscript letters are significantly different; $P<0.05$ (paired comparison by

least-squares-means procedure with Tukey's adjustment after establishment of a significant $F$ test by ANOVA).

relative area of the densitometric scan $<25.5 \mathrm{~nm}$. The absolute concentration of cholesterol in the LDL subfraction with a diameter $<25.5 \mathrm{~nm}\left(\mathrm{LDL}-\mathrm{cholesterol}_{<25.5 \mathrm{~nm}}\right)$ was estimated by multiplying the total plasma LDL-cholesterol levels by the relative proportion of LDL with a diameter $<25.5 \mathrm{~nm}$ as described previously ${ }^{3}$. A similar approach was used to estimate the relative and absolute concentration of cholesterol in the LDL subfraction with a diameter $>26.0 \mathrm{~nm}$ (LDL $\%>260 \mathrm{~nm}$ and LDLcholesterol $_{>260 \mathrm{~nm}}$ respectively). The $\mathrm{CV}$ for the measurements of LDL $\%_{<25.5 \mathrm{~nm}}$ and LDL $\%>260 \mathrm{~nm}$ were 12.0 and $9.3 \%$ respectively.

\section{Statistical analysis}

All data are expressed as means and standard deviations unless stated otherwise. The significance of the differences between baseline periods (week 0) and treatment periods with different diets (week 4) were assessed by the least square mean test for repeated measures with the Tukey multi-comparison adjustment using the PROC MIXED procedure (version 8.1; SAS Institute Inc., Cary, NC, USA). Introduction of appropriate interaction terms in this analytical procedure showed that there was no interaction between sex and treatment. Association between diet-induced changes (week $4 v .0$ ) in metabolic variables and changes in the various LDL electrophoretic characteristics were tested with Spearman rank correlation analysis. Differences in nutritional profiles between treatments were investigated using paired comparisons and least-squaremean procedure with Tukey's adjustment after establishment of a significant $F$ test by ANOVA. For analyses based on CRP subgroups, LDL-cholesterol $<25.5 \mathrm{~nm}$ values of subjects with CRP levels $>10 \mathrm{mg} / \mathrm{l}$ at any time point were excluded from analysis. Statistical significance was defined as $P<0.05$.

\section{Results}

As reported previously, compliance to the dietary regimens was good, with a mean value of $93 \%$ of all calories provided recorded as consumed ${ }^{17}$. There was no significant difference in participants' body weight at week 4 of each treatment (control diet 75.9 (SD 2.2) kg; statin treatment 76.2 (SD 2.2) kg; dietary portfolio $76.4($ SD $2 \cdot 3) \mathrm{kg}$ ).

\section{Blood lipids}

As indicated in a previous report ${ }^{17}$, significant reductions in blood lipids were seen during the treatment periods (Table 3), including reductions from baseline in LDL-cholesterol levels of -8.5 (SD 1.9) $\%,-33.3$ (SD 1.9) $\%$ and -29.6 (SD 1.3) \% with the control diet, the statin treatment and the dietary portfolio, respectively.

\section{LDL size phenotype}

None of the three treatments had a significant effect on LDLPPD or LDL integrated size (Table 3). Also, as shown in Table 3, there was no significant change in the relative proportion of LDL subclasses after any treatments. Change in plasma TAG concentrations were correlated with variation in LDL-PPD within the statin and control phases $(r-0.39$, $P=0.02 ; \mathrm{r}-0.61, P<0.001)$ but not within the dietary portfolio period ( $\mathrm{r}-0.06, P=0.76$ ). However, as shown in Fig. 1, the dietary portfolio and the statin treatment significantly reduced the estimated cholesterol concentrations in the small as well as in the large LDL subclasses, LDL-cholesterol $<25.5 \mathrm{~nm}$ showing the greatest reduction. The reduction in LDL-cholesterol $<25.5 \mathrm{~nm}$ levels after the dietary portfolio $(-0.69(\mathrm{SE} 0.10) \mathrm{mmol} / \mathrm{l})$ and the statin treatment $(-0.99(\mathrm{SE} 0.10) \mathrm{mmol} / \mathrm{l})$ were significantly greater than after the control diet $(-0.17$ (SE 0.08) mmol/l). However, changes in LDL-cholesterol $<25.5 \mathrm{~nm}$ levels were not significantly different between the dietary portfolio and the statin treatment. The reduction in LDL-cholesterol $>26.0 \mathrm{~nm}$ levels were not different between all three treatments. When posttreatment values were tested rather than change from baseline, similar results were obtained. Subgroup analysis using the median distribution of LDL-PPD $(25.25 \mathrm{~nm})$ indicated that the reduction in LDL-cholesterol $<25.5 \mathrm{~nm}$ levels after 4 weeks 
Table 3. Effect of control diet, dietary portfolio and statin treatment on plasma lipids* ${ }^{*}$ C-reactive proteins $\dagger$ and LDL electrophoretic characteristics of hyperlipidaemic subjects $\|$

(Mean values with their standard errors for thirty-four subjects)

\begin{tabular}{|c|c|c|c|c|c|c|c|c|c|c|c|c|c|}
\hline \multirow{3}{*}{ Variables } & \multicolumn{4}{|c|}{ Control diet } & \multicolumn{4}{|c|}{ Dietary portfolio } & \multicolumn{4}{|c|}{ Statin treatment } & \multirow[b]{3}{*}{$P$ for interaction§ } \\
\hline & \multicolumn{2}{|c|}{ Week 0} & \multicolumn{2}{|c|}{ Week 4} & \multicolumn{2}{|c|}{ Week 0} & \multicolumn{2}{|c|}{ Week 4} & \multicolumn{2}{|c|}{ Week 0} & \multicolumn{2}{|c|}{ Week 4} & \\
\hline & Mean & SEM & Mean & SEM & Mean & SEM & Mean & SEM & Mean & SEM & Mean & SEM & \\
\hline Total cholesterol $(\mathrm{mmol} / \mathrm{l}) \ddagger$ & 6.79 & 0.16 & $6 \cdot 23$ & $0.15^{\mathrm{a}}$ & 6.76 & 0.15 & $5 \cdot 25$ & $0.12^{\mathrm{b}}$ & 6.84 & 0.15 & 4.97 & $0.17^{\mathrm{b}}$ & $<0.001$ \\
\hline LDL-cholesterol $(\mathrm{mmol} / \mathrm{l})$ & 4.56 & 0.14 & 4.13 & $0.13^{\mathrm{a}}$ & 4.51 & 0.12 & 3.17 & $0.09^{\mathrm{b}}$ & 4.49 & 0.12 & 2.91 & $0.10^{\mathrm{b}}$ & $<0.001$ \\
\hline HDL-cholesterol (mmol/l/) & 1.24 & 0.05 & 1.11 & 0.04 & 1.23 & 0.05 & $1 \cdot 15$ & 0.05 & 1.24 & 0.06 & $1 \cdot 17$ & 0.06 & 0.16 \\
\hline TAG $(\mathrm{mmol} / \mathrm{l})$ & $2 \cdot 17$ & 0.16 & $2 \cdot 18$ & 0.16 & $2 \cdot 24$ & 0.18 & 2.04 & 0.18 & 2.45 & 0.19 & 1.96 & 0.18 & $0.001^{\star *}$ \\
\hline Aро B $(g / /) \ddagger$ & 1.45 & 0.04 & 1.34 & $0.03^{\mathrm{a}}$ & 1.43 & 0.04 & 1.09 & $0.03^{\mathrm{b}}$ & 1.46 & 0.03 & 1.02 & $0.04^{\mathrm{b}}$ & $<0.001$ \\
\hline C-reactive protein (mg/l) & 1.94 & 0.30 & 1.76 & 0.28 & $2 \cdot 28$ & 0.48 & 1.97 & 0.55 & 2.61 & 0.45 & 2.84 & 1.30 & 0.19 \\
\hline \multicolumn{14}{|l|}{ LDL particle size phenotype } \\
\hline LDL-peak particle diameter $(\AA)$ & 253.0 & 0.4 & $252 \cdot 8$ & 0.4 & 253.0 & 0.4 & 253.0 & 0.4 & $252 \cdot 7$ & 0.5 & $253 \cdot 0$ & 0.5 & 0.42 \\
\hline LDL-integrated size $(\AA)$ & 254.0 & 0.4 & 253.8 & 0.4 & $253 \cdot 6$ & 0.3 & 253.8 & 0.4 & 253.5 & 0.4 & 254.0 & 0.4 & 0.24 \\
\hline $\mathrm{LDL}_{>26.0 \mathrm{~nm}}(\%)$ & 21.8 & 1.4 & 20.7 & 1.3 & $21 \cdot 1$ & $1 \cdot 2$ & 20.5 & 1.3 & $19 \cdot 6$ & 1.5 & 20.4 & 1.3 & 0.65 \\
\hline $\mathrm{LDL}_{25.5-26.0 \mathrm{~nm}(\%)}$ & 24.4 & 0.9 & 23.5 & 0.9 & $24 \cdot 3$ & $1 \cdot 1$ & $23 \cdot 3$ & 1.0 & 23.2 & 1.0 & $25 \cdot 7$ & $2 \cdot 1$ & $0 \cdot 10$ \\
\hline $\mathrm{LDL}_{<25.5 \mathrm{~nm}}(\%)$ & 53.8 & $2 \cdot 1$ & $55 \cdot 7$ & $2 \cdot 1$ & 54.6 & $2 \cdot 2$ & $56 \cdot 1$ & $2 \cdot 0$ & 57.2 & $2 \cdot 1$ & 54.0 & $2 \cdot 7$ & 0.11 \\
\hline LDL-cholesterol $_{25.5-26.0 \mathrm{~nm}}(\mathrm{mmol} / \mathrm{l}) \ddagger$ & $1 \cdot 11$ & 0.05 & 0.97 & $0.05^{\mathrm{a}}$ & $1 \cdot 10$ & 0.06 & 0.74 & $0.03^{\mathrm{b}}$ & 1.05 & 0.06 & 0.76 & $0.07^{b}$ & 0.001 \\
\hline
\end{tabular}

*Adapted from Jenkins et al. ${ }^{17}$

F The main effect of the diet was significant $(P<0.05)$

SInteraction between treatment and time.

$\|$ For details of subjects and procedures, see Subjects and methods.

(hignificantly different; $P<0.05$ (assessed by the least square mean test with the Tukey multi-comparison adjustment using the PROC MIXED procedure). ${ }^{* *}$ For TAG only week 2 showed significant time differences between treatment. They are not shown in this table. 
(A)

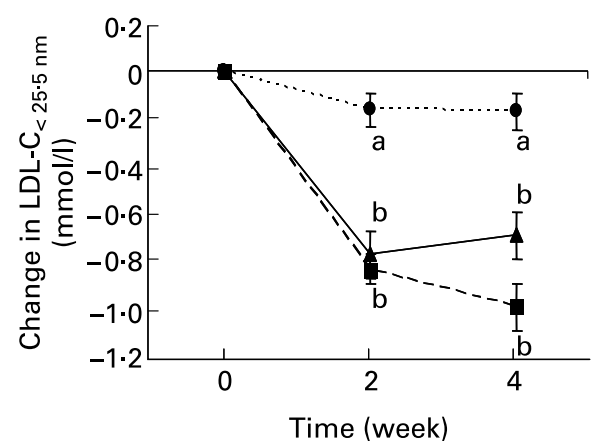

(B)

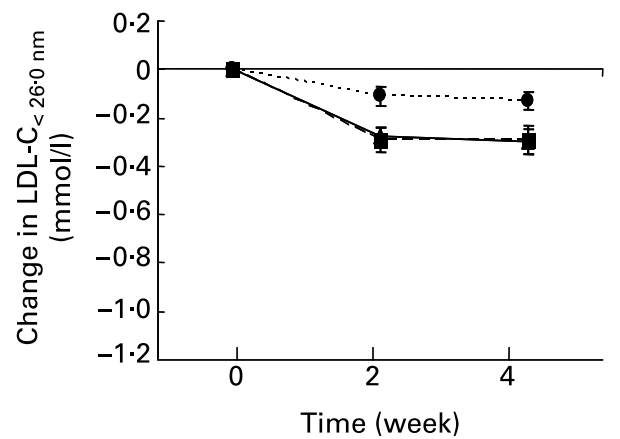

of treatment on the dietary portfolio was 2-fold greater in the group with LDL-PPD below the median at baseline than in the group with LDL-PPD above the median (-1.06 (SE 0.16) $v$. -0.42 (SE 0.13 ) mmol/l, $P=0.01$ ) (data not shown). As indicated in Subjects and methods, there was no significant interaction between sex and treatment effects.

\section{Particle size change and $C$-reactive protein}

Additional subgroup analyses were also undertaken to assess the impact of the pro-inflammatory status at baseline on the responsiveness to treatment. Subjects were categorized into three subgroups on the basis of their plasma CRP levels at baseline for each treatment, which were defined as low $(<1 \mathrm{mg} / \mathrm{l})$, moderate $(1-3 \mathrm{mg} / \mathrm{l})$ or high $(>3 \mathrm{mg} / \mathrm{l})^{34}$. As shown in Fig. 2, on the dietary portfolio, subjects with plasma CRP levels $<3 \mathrm{mg} / \mathrm{l}$ at baseline showed significant reduction in LDL-cholesterol $<25.5 \mathrm{~nm}$ concentrations after 4 weeks, while there was no significant change in the group with plasma CRP levels $>3 \mathrm{mg} / \mathrm{l}(-0.27$ (SE 0.20$) \mathrm{mg} / \mathrm{l})$. Similar results were obtained when subjects were categorized into two groups (CRP $>$ or $<3 \mathrm{mg} / \mathrm{l})$ rather than three groups (data not shown). The impact of the statin treatment and the control diet on LDL-cholesterol $<25.5 \mathrm{~nm}$ was virtually unaltered by plasma CRP level at baseline.

\section{Discussion}

The significant reduction in LDL-cholesterol concentrations with the combination diet containing phytosterols, soluble fibres, soya proteins and almonds has been previously described in this same sample of subjects ${ }^{17}$. The objective of the present study was to directly compare the effect of this dietary portfolio with the effect of statin treatment on other atherogenic characteristics of LDL particles, specifically LDL-PPD and the estimated cholesterol levels among the various LDL subclasses. Our data indicated that the dietary portfolio, like the statin treatment, despite having virtually no impact on the predominant LDL subfraction in these subjects, led to a preferential reduction in the estimated cholesterol concentration among the small LDL particles. Results from the Quebec Cardiovascular Study have indicated that LDL-cholesterol $<25.5 \mathrm{~nm}$ concentrations were strongly and independently associated with an increased risk of CHD in a cohort of more than 2000 men followed for 13 years ${ }^{3}$. Based on the Quebec Cardiovascular study data, the $0.69 \mathrm{mmol} / \mathrm{l}$ reduction in estimated cholesterol levels within the small LDL subfraction attributable to the dietary portfolio would translate into a clinically meaningful $19 \%$ reduction in the 13 -year risk of CHD. The present data also suggested that baseline inflammatory status may partly influence the responsiveness of the LDL size phenotype to the dietary portfolio.
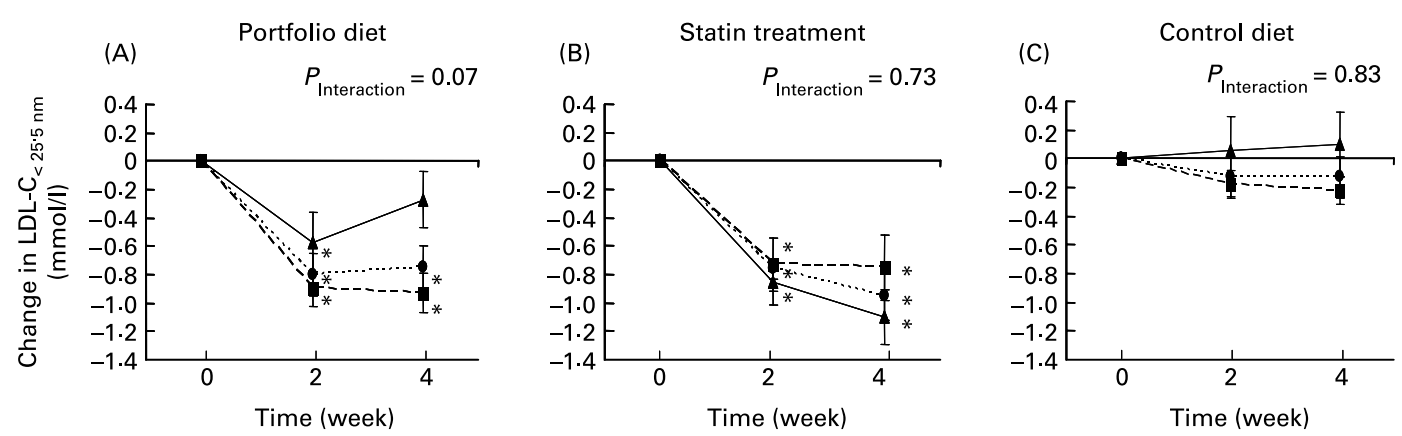

Fig. 2. Change from baseline in plasma cholesterol concentration among the small LDL particles (LDL-cholesterol (LDL-C) $<25.5 \mathrm{~nm})$ according to baseline plasma C-reactive protein (CRP) levels $(<1 \mathrm{mg} / \mathrm{l}(\bullet), 1-3 \mathrm{mg} / \mathrm{l}(\boldsymbol{\square}),>3 \mathrm{mg} / \mathrm{l}(\boldsymbol{\Lambda}))$ in hyperlipidaemic subjects after the dietary portfolio $(\mathrm{A})$, statin treatment $(\mathrm{B})$ or the control diet (C) The interaction of group of CRP by time was tested using absolute values. Values are means with their standard errors. Mean values are significantly different from baseline; ${ }^{\star} P<0.05$. For details of subjects and procedures, see Subjects and methods. 
In a previous report, we have shown that the dietary portfolio was associated with a reduction in the proportion of larger LDL particles and an increase in the proportion of small particles with a corresponding diminution in the LDL integrated $\operatorname{size}^{28}$. There was also a significant reduction in $\mathrm{LDL}_{\text {-cholesterol }}<25 \cdot 5 \mathrm{~nm}$ levels ${ }^{28}$. In the present study, subjects had higher plasma TAG levels at baseline than participants in our previous report. Because plasma TAG levels have been shown to modulate LDL size phenotype, differences in plasma TAG levels may partly explain the inconsistencies noted between these two studies.

Only limited data existed on the individual impact of components on the dietary portfolio and the LDL particle size phenotype. To our knowledge, four studies have investigated the impact of phytosterols on LDL particle size phenotype. Consumption of phytosterol and stanol in various forms has generally been associated with no change in features of the LDL size phenotype ${ }^{19,20,23}$ but a recent study has shown a significant reduction in estimated cholesterol levels in all LDL particle subclasses with the consumption of $1.8 \mathrm{~g}$ phytosterols daily $^{26}$. Based on these inconsistent results, we hypothesize that phytosterols may exert only limited effects on LDL size.

To the best of our knowledge, three studies have examined the impact of soya bean proteins on LDL particle phenotype. Two studies conducted in normocholesterolaemic and mildly hypercholesterolaemic women consuming their habitual diets reported that supplementation with isolated soya protein powder (low or high in isoflavones) had no impact on LDL$\mathrm{PPD}^{24,25}$. We have shown in a more recent controlled study that consumption of soya protein produced an important redistribution of LDL from small to larger particles and a significant reduction in the proportion of LDL with a diameter $<25.5 \mathrm{~nm}(\mathrm{LDL} \%<25.5 \mathrm{~nm})^{22}$.

Two studies have examined the effect of soluble fibres on the LDL size phenotype. The first study found that consumption of high-fibre oat cereals lowered cholesterol concentration among the small LDL subclass while wheat cereals increased cholesterol among this LDL subclass ${ }^{21}$. Another study conducted in hypercholesterolaemic subjects has shown that consumption of diets containing barley significantly reduced LDL-cholesterol $_{>260 \mathrm{~nm}}$ compared with a Step 1 diet of the American Heart Association, but had no significant effect on

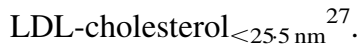

The impact of almonds on LDL particle size has not been clearly established. One study has compared the impact of a usual diet with or without walnut and a low-fat diet with or without walnut on LDL size characteristics ${ }^{18}$. Results of this study indicated that there was a decrease in the cholesterol concentration of the small LDL subfraction on the usual diet with walnut compared with the usual diet solely.

The literature on the different components of the dietary portfolio suggests that each component has either beneficial effects or simply no impact on LDL size phenotype. The phytosterol component of the dietary portfolio tends to have a very minor impact on the LDL size phenotype. However, soya protein, soluble fibres and nuts are most likely responsible for the beneficial change in the estimated cholesterol levels in small LDL particles seen with the dietary portfolio.

Statins are effective LDL-cholesterol lowering agents ${ }^{6}$. In the present study, $20 \mathrm{mg}$ lovastatin daily produced no change in LDL-PPD or LDL integrated size. However, lovastatin produced a significant reduction in estimated cholesterol levels among all LDL particle subclasses. TillyKiesi et al. have shown that lovastatin treatment for 12 weeks at a starting dose of $40 \mathrm{mg}$ produced no mean change in LDL distribution ${ }^{13}$. Several other studies have examined the effects of statins on LDL size phenotype, but few have tested lovastatin. A majority of studies have shown that the principal benefit from statin treatment (principally atorvastatin and fluvastatin) on LDL size phenotype was reduction in cholesterol within the denser LDL particles fraction ${ }^{9-11}$, as seen in the present study. The dietary portfolio and the statin treatment had a comparable impact on LDL-

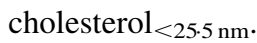

Data from the present study are consistent with previous observations from our group in showing that subjects with smaller LDL-PPD at baseline (LDL-PPD $<25.25 \mathrm{~nm}$ ) had a greater reduction in estimated cholesterol levels within the small LDL subfraction with the portfolio treatment ${ }^{28}$. This was also seen with the statin treatment (data not shown).

There is an increasing body of evidence indicating that the inflammatory status at baseline may predict the response to dietary changes. In the present study, additional subgroup analysis revealed that baseline CRP levels modulated the LDL-cholesterol $<25.5 \mathrm{~nm}$ response to the dietary portfolio. Subjects with low or moderate baseline CRP levels $(<3.0 \mathrm{mg} / \mathrm{l})$ showed significantly greater reduction in LDLcholesterol $_{<25.5 \mathrm{~nm}}$ levels after the dietary portfolio than subjects with high baseline CRP levels $(>3.0 \mathrm{mg} / \mathrm{l})$. Hilpert et al. ${ }^{31}$ have recently shown that subjects with low CRP exhibited significant reductions in LDL-cholesterol levels with a low-fat diet, whereas subjects with high CRP showed increased LDL-cholesterol concentrations. Subanalyses of the DASH diet study also indicated that LDL-cholesterol levels were significantly reduced only in subjects with baseline CRP below the median $(<2 \cdot 37 \mathrm{mg} / \mathrm{l})^{30}$. Furthermore, we have recently shown that plasma total and VLDL-TAG levels were significantly increased in subjects with high baseline CRP levels after a low-fat diet, but remained unchanged in the subgroup with low CRP concentration at baseline ${ }^{29}$. Taken together, these results suggest that baseline CRP level, a non-specific marker of low-grade inflammation, might predict individual variation in the response to dietary changes including change in the LDL size phenotype in response to the dietary portfolio. Mechanisms inherent to this phenomenon remain theoretical. It has been suggested that a pro-inflammatory state may be associated with an increased psychological or environmental stress ${ }^{35}$. We have also hypothesized that major dietary modifications within a rigorously controlled study may be perceived as further physiological stress in subjects who already have elevated CRP levels at baseline and this may partly explain why these individuals display an attenuated or even an undesirable response to dietary interventions ${ }^{29}$. Whether a high baseline CRP also identifies a group in need of statin therapy, i.e. those who would not benefit from diet in terms of small dense particle reduction, will have to be determined by further studies.

In conclusion, the present study has shown that a portfolio of cholesterol-lowering foods from vegetable sources, like several first and second generation statins, has only a minor impact on several features of the small dense LDL phenotype. However, the preferential reduction in the estimated concentration of 
cholesterol within the smallest subclass of LDL particles after the dietary portfolio, compared with the low-fat National Cholesterol Education Program Step II diet, is likely to confer additional cardiovascular benefits. Our findings also provide further support to the thesis that baseline inflammatory status may partly influence the responsiveness of lipid risk factors to dietary manipulations. Additional research is required to test the long-term effect of the dietary portfolio on plasma lipids and LDL size phenotype.

\section{Acknowledgements}

This study was supported financially or through the donation of food by Canada Research Chair Endowment of the Federal Government of Canada, the Canadian Natural Sciences and Engineering Research Council of Canada, Loblaw Brands Ltd (Toronto), Unilever Canada (Toronto), the Almond Board of California (Modesto, CA), the Hain-Celestial Group (Melville, NY), Kraft Foods (Glenview, IL), Procter \& Gamble Inc (Toronto), Pepsico Foods Canada-Quaker Peterborough Plant (Peterborough, Canada), Nestlé Canada Inc (Pickering, Canada), Bartlett Farms, Barwell Food Sales Inc (London, Canada), and Burnbrae Farms (Upton, Canada). D.J.A.J. has served on the Scientific Advisory Board of Unilever and Solae. D.J.A.J. and C.W.C.K. have been on the speaker's panel for the Almond Board of California (Modesto, CA). C.W.C.K., D.A.F. and T.L.P. received partial salary funding from a research grant provided by Unilever, Loblaw Brands Ltd and the Almond Board of California. E.A.T. is employed by Unilever Health Institute, Unilever R\&D Vlaardingen, Netherlands. K.G.L. is employed by the Almond Board of California.

\section{References}

1. Krauss RM \& Burke DJ (1982) Identification of multiple subclasses of plasma low density lipoproteins in normal humans. J Lipid Res 23, 97-104.

2. Lamarche B, Tchernof A, Moorjani S, Cantin B, Dagenais GR, Lupien PJ \& Despres JP (1997) Small, dense low-density lipoprotein particles as a predictor of the risk of ischemic heart disease in men. Prospective results from the Quebec Cardiovascular Study. Circulation 95, 69-75.

3. St Pierre AC, Ruel IL, Cantin B, Dagenais GR, Bernard PM, Despres JP \& Lamarche B (2001) Comparison of various electrophoretic characteristics of LDL particles and their relationship to the risk of ischemic heart disease. Circulation 104, $2295-2299$.

4. Scandinavian Simvastatin Survival Study Group (1994) Randomised trial of cholesterol lowering in 4444 patients with coronary heart disease: the Scandinavian Simvastatin Survival Study (4S). Lancet 344, 1383-1389.

5. Anon MRC/BHF (2002) Heart Protection Study of cholesterol lowering with simvastatin in 20,536 high-risk individuals: a randomised placebo-controlled trial. Lancet 360, 7-22.

6. Grundy SM (1988) HMG-CoA reductase inhibitors for treatment of hypercholesterolemia. $N$ Engl J Med 319, 24-33.

7. Zhao SP, Hollaar L, 't Hooft FM, Smelt AH, Gevers JA \& van der Leuven LA (1991) Effect of simvastatin on the apparent size of LDL particles in patients with type IIB hyperlipoproteinemia. Clin Chim Acta 203, 109-117.

8. Yuan JN, Tsai MY, Hegland J \& Hunninghake DB (1991) Effects of fluvastatin (XU 62-320), an HMG-CoA reductase inhibitor, on the distribution and composition of low density lipoprotein subspecies in humans. Atherosclerosis 87, 147-157.

9. Forster LF, Stewart G, Bedford D, Stewart JP, Rogers E, Shepherd J, Packard CJ \& Caslake MJ (2002) Influence of atorvastatin and simvastatin on apolipoprotein $\mathrm{B}$ metabolism in moderate combined hyperlipidemic subjects with low VLDL and LDL fractional clearance rates. Atherosclerosis $\mathbf{1 6 4}$ $129-145$.

10. Guerin M, Egger P, Soudant C, Le Goff W, van Tol A, Dupuis R \& Chapman MJ (2002) Dose-dependent action of atorvastatin in type IIB hyperlipidemia: preferential and progressive reduction of atherogenic apoB-containing lipoprotein subclasses (VLDL-2, IDL, small dense LDL) and stimulation of cellular cholesterol efflux. Atherosclerosis 163, 287-296.

11. Marz W, Scharnagl H, Abletshauser C, Hoffmann MM, Berg A, Keul J, Wieland H \& Baumstark MW (2001) Fluvastatin lowers atherogenic dense low-density lipoproteins in postmenopausal women with the atherogenic lipoprotein phenotype. Circulation 103, 1942-1948.

12. Superko HR, Krauss RM \& DiRicco C (1997) Effect of fluvastatin on low-density lipoprotein peak particle diameter. Am J Cardiol 80, 78-81.

13. Tilly-Kiesi M (1991) The effect of lovastatin treatment on lowdensity lipoprotein hydrated density distribution and composition in patients with intermittent claudication and primary hypercholesterolemia. Metabolism 40, 623-628.

14. Yu-Poth S, Zhao G, Etherton T, Naglak M, Jonnalagadda S \& Kris-Etherton PM (1999) Effects of the National Cholesterol Education Program's Step I and Step II dietary intervention programs on cardiovascular disease risk factors: a meta-analysis. Am J Clin Nutr 69, 632-646.

15. Anon (2001) Executive Summary of The Third Report of The National Cholesterol Education Program (NCEP) Expert Panel on Detection, Evaluation, And Treatment of High Blood Cholesterol In Adults (Adult Treatment Panel III). JAMA 285, 2486-2497.

16. Krauss RM, Eckel RH, Howard B, et al. (2000) AHA Dietary Guidelines: revision 2000: A statement for healthcare professionals from the Nutrition Committee of the American Heart Association. Circulation 102, 2284-2299.

17. Jenkins DJ, Kendall CW, Marchie A, et al. (2005) Direct comparison of a dietary portfolio of cholesterol-lowering foods with a statin in hypercholesterolemic participants. Am J Clin Nutr 81, 380-387.

18. Almario RU, Vonghavaravat V, Wong R \& Kasim-Karakas SE (2001) Effects of walnut consumption on plasma fatty acids and lipoproteins in combined hyperlipidemia. Am J Clin Nutr 74, $72-79$.

19. Charest A, Desroches S, Vanstone CA, Jones PJ \& Lamarche B (2004) Unesterified plant sterols and stanols do not affect LDL electrophoretic characteristics in hypercholesterolemic subjects. J Nutr 134, 592-595.

20. Charest A, Vanstone C, St Onge MP, Parson W, Jones PJ \& Lamarche B (2005) Phytosterols in nonfat and low-fat beverages have no impact on the LDL size phenotype. Eur J Clin Nutr 59, 801-804.

21. Davy BM, Davy KP, Ho RC, Beske SD, Davrath LR \& Melby CL (2002) High-fiber oat cereal compared with wheat cereal consumption favorably alters LDL-cholesterol subclass and particle numbers in middle-aged and older men. Am J Clin Nutr 76, 351-358.

22. Desroches S, Mauger JF, Ausman LM, Lichtenstein AH \& Lamarche B (2004) Soy protein favorably affects LDL size independently of isoflavones in hypercholesterolemic men and women. $J$ Nutr 134, 574-579.

23. Matvienko OA, Lewis DS, Swanson M, Arndt B, Rainwater DL, Stewart J \& Alekel DL (2002) A single daily dose of soybean 
phytosterols in ground beef decreases serum total cholesterol and LDL cholesterol in young, mildly hypercholesterolemic men. Am J Clin Nutr 76, 57-64.

24. Merz-Demlow BE, Duncan AM, Wangen KE, Xu X, Carr TP, Phipps WR \& Kurzer MS (2000) Soy isoflavones improve plasma lipids in normocholesterolemic, premenopausal women. Am J Clin Nutr 71, 1462-1469.

25. Wangen KE, Duncan AM, Xu X \& Kurzer MS (2001) Soy isoflavones improve plasma lipids in normocholesterolemic and mildly hypercholesterolemic postmenopausal women. Am $J$ Clin Nutr 73, 225-231.

26. Varady KA, St Pierre AC, Lamarche B \& Jones P (2005) Effect of plant sterols and endurance training on LDL particle size and distribution in previously sedentary hypercholesterolemic adults. Eur J Clin Nutr 59, 518-525.

27. Behall KM, Scholfield DJ \& Hallfrisch J (2004) Diets containing barley significantly reduce lipids in mildly hypercholesterolemic men and women. Am J Clin Nutr 80, $1185-1193$.

28. Lamarche B, Desroches S, Jenkins DJ, et al. (2004) Combined effects of a dietary portfolio of plant sterols, vegetable protein, viscous fibre and almonds on LDL particle size. Br J Nutr 92, 657-663.

29. Desroches S, Archer WR, Paradis ME, Deriaz O, Couture P, Bergeron J, Bergeron N \& Lamarche B (2006) Baseline plasma C-reactive protein concentrations influence lipid and lipoprotein responses to low-fat and high monounsaturated fatty acid diets in healthy men. $J$ Nutr 136, 1005-1011.

30. Erlinger TP, Miller ERIII, Charleston J \& Appel LJ (2003) Inflammation modifies the effects of a reduced-fat low-cholesterol diet on lipids: results from the DASH-sodium trial. Circulation 108, 150-154.

31. Hilpert KF, Kris-Etherton PM \& West SG (2005) Lipid response to a low-fat diet with or without soy is modified by C-reactive protein status in moderately hypercholesterolemic adults. J Nutr 135, 1075-1079.

32. Jenkins DJ, Kendall CW, Marchie A, et al. (2005) Direct comparison of dietary portfolio vs statin on C-reactive protein. Eur J Clin Nutr 59, 851-860.

33. Jenkins DJ, Kendall CW, Faulkner D, et al. (2002) A dietary portfolio approach to cholesterol reduction: combined effects of plant sterols, vegetable proteins, and viscous fibers in hypercholesterolemia. Metabolism 51, 1596-1604.

34. Pearson TA, Mensah GA, Alexander RW, et al. (2003) Markers of inflammation and cardiovascular disease: application to clinical and public health practice: A statement for healthcare professionals from the Centers for Disease Control and Prevention and the American Heart Association. Circulation 107, 499-511.

35. Yudkin JS, Kumari M, Humphries SE \& Mohamed-Ali V (2000) Inflammation, obesity, stress and coronary heart disease: is interleukin-6 the link? Atherosclerosis 148, 209-214. 